Original Article

\title{
A SIMPLE (HPLC-UV) METHOD FOR THE QUANTIFICATION OF COLCHICINE IN BULK AND ETHOSOMAL GEL NANO-FORMULATION AND ITS VALIDATION
}

\author{
IBRAHIM M. ABDULBAQI, YUSRIDA DARWIS*, NURZALINA ABDUL KARIM KHAN, REEM ABOU ASSI, \\ GABRIEL ONN KIT LOH
}

\author{
School of Pharmaceutical Sciences, Universiti Sains Malaysia, 11800 Minden, Pulau Penang, Malaysia \\ Email: yusrida@usm.my
}

Received: 07 Mar 2017 Revised and Accepted: 19 May 2017

\begin{abstract}
Objective: To develop and validate a stability-indicating reversed phase high-performance liquid chromatography (RP-HPLC) method for the determination of colchicine in bulk and ethosomal gel nano-formulation.

Methods: The chromatographic conditions were optimized using stainless steel Hypersil Gold C-18 analytical column with the dimensions of $250 \mathrm{~mm} \times 4.6 \mathrm{~mm}$ ID $\times 5 \mu \mathrm{m}$. The mobile phase consisted of acetonitrile and ammonium acetate buffer $(20 \mathrm{mmol} / \mathrm{l}, \mathrm{pH}=4.85)$ in the ratio of $32: 68 \mathrm{v} / \mathrm{v}$. The flow rate was set at $1 \mathrm{ml} / \mathrm{min}$ and the detection wavelength was $353 \mathrm{~nm}$. The column was maintained at $30{ }^{\circ} \mathrm{C}$ and the injection volume was $10 \mu \mathrm{l}$. The stability of colchicine in different conditions was investigated by exposing the drug to stress degradation using acid, base, oxidation, heat and light.
\end{abstract}

Results: There was no interference from excipients, impurities, dissolution media or degradation products at the retention time of colchicine 5.9 min indicating the specificity of the method. The limit of detection (LOD) and the limit of quantification (LOQ) were $8.64 \mathrm{ng} / \mathrm{ml} \mathrm{and} 26.17 \mathrm{ng} / \mathrm{ml}$ respectively. The drug showed good stability under heat, acid, oxidation and light, but substantial degradation was observed under alkali condition. The procedure was validated for specificity, linearity, accuracy and precision.

Conclusion: A simple, rapid, specific and stability-indicating HPLC-UV method for the determination of colchicine in the pure and ethosomal gel was successfully developed. The developed method was statistically confirmed to be accurate, precise, and reproducible.

Keywords: Colchicine, Ethosomal gel, HPLC-UV, Specificity

(C) 2017 The Authors. Published by Innovare Academic Sciences Pvt Ltd. This is an open access article under the CC BY license (http://creativecommons.org/licenses/by/4.0/) DOI: http://dx.doi.org/10.22159/ijpps.2017v9i7.18336

\section{INTRODUCTION}

Colchicine $\quad(\mathrm{N}-[(7 \mathrm{~S})-1,2,3,10-T e t r a m e t h o x y-9-0 x 0-5,6,7,9-t e t r a-$ hydrobenzo[a]heptalen-7-yl]acetamide) has a molecular weight of 399.437, and the molecular formula $\mathrm{C}_{22} \mathrm{H}_{25} \mathrm{NO}_{6}$ is shown in fig 1 [1]. It is a potent alkaloid obtained from the dried corns and seeds of plants of the genus Colchicum which belong to Liliaceae family. Among this family, the commonly used plants are Colchicum autumnale "meadow saffron" and Colchicum autumn crocus [2-4].

Colchicine has been used for the treatment of acute gout since more than $2000 \mathrm{y}$ ago. It was also used to treat pseudogout and familial Mediterranean fever for several decades. It is highly effective in the treatment of acute gout, especially when given in the first $12-36 \mathrm{~h}$ of the gouty attack [3]. However, colchicine for the treatment of acute gout was only approved by the United States food and drug administration (FDA) in 2009, although colchicine tablets have been prescribed in the United States since the 19th century [5].<smiles></smiles>

Fig. 1: The chemical structure of colchicine [1]
Ethosomal nanocarriers are lipid based vesicular systems, especially designed for the delivery of therapeutic agents dermally/ transdermally. Numerous ethosomal gels of highly diverse therapeutic agents have been developed and the interest in these formulations is increasing, and they are attracting the attention of many researchers [6-8]. Thus, the need for accurate, simple and sensitive analytical methods to quantify and evaluate the release behaviour of drugs from these formulations is also increasing.

The first few analytical methods developed for the determination of colchicine were involving colorimetric, fluorometric assay, radioimmunoassay, and thin layer chromatography-densitometry methods [9-13]. Based on the literature review, only few methods involving the high-performance liquid chromatography with UV detection are available for determination of colchicine in pharmaceutical formulations [12, 14-17]. Other HPLC-UV methods are reported to detect and quantify the drug in biological fluids and samples [14, 18-21]. Several methods using liquid chromatography coupled with mass spectrometry or tandem mass spectrometry, and gas chromatography/mass spectrometry were also reported to determine colchicine in different biological fluids [22-28], but these methods are time-consuming, complicated, and expensive in comparison to a simple HPLC-UV method. To the best of our knowledge, until now there is no stability indicating HPLC-UV method for the determination of colchicine has been developed. The aim of this study is to develop a simple, rapid, specific and stabilityindicating HPLC-UV method for detection and quantification of colchicine in bulk and ethosomal gel formulation. In this work, the linearity range of the calibration curve was extended to make the method suitable for the assay, and also for the in vitro release studies of the drug from the prepared ethosomal gel formulation. The method was validated as per the international conference on 
harmonization of technical requirements for registration of pharmaceuticals for human use (ICH) guidelines [29].

\section{MATERIALS AND METHODS}

\section{Chemicals and reagents}

Colchicine (purity $>97$ ) was purchased from Acros organics, New Jersey, USA. Acetonitrile (HPLC grade) was purchased from J. T. Baker, Phillipsburg, USA. Ammonium acetate was bought from Bendosen laboratory chemicals, Norway.

Glacial acetic acid was obtained from QRëC, Selangor, Malaysia. Phospholipon $90 \mathrm{G}^{\circledR}$ was generously donated by Lipoid LLC, New Jersey, USA. Tween $20^{\circledR}$ was purchased from R and M chemicals, Essex, UK. Carbopol $940^{\circledR}$ was a kind gift from Lubrizol Corporation, Ohio, USA. Absolute ethanol (purity 99.7) was bought from Fine Chemicals Inc., USA. Ultrapure water was prepared by Elga Purelab classic UVF water purification system, France. All other organic solvents and chemicals used were either of analytical reagent or of the high-performance liquid chromatography grade.

\section{Instrumentation}

The HPLC system was comprised of a Shimadzu (VP series, Kyoto, Japan) pump (LC-20AT VP) with solvent cabinet, a degasser (DGU$20 \mathrm{~A}_{3}$ ), a column oven (CTO-10S VP), an auto-injector (SIL20A HT VP), UV/VIS detector (SPD-20AD VP) and a computer software (LabSolutions ${ }^{\circledR}$ Version 5.30 SP1).

\section{Chromatographic conditions}

The chromatographic separation was performed using a Hypersil Gold C-18 analytical column with the dimensions of $250 \mathrm{~mm} x$ $4.6 \mathrm{~mm}$ ID x $5 \mu \mathrm{m}$, Fisher Scientific, USA. The flow rate was set at $1 \mathrm{ml} / \mathrm{min}$ and detection wavelength was $353 \mathrm{~nm}$. The column was maintained at $30{ }^{\circ} \mathrm{C}$ and an injection volume of $10 \mu \mathrm{l}$ was used. The mobile phase consisted of acetonitrile: ammonium acetate buffer $(20 \mathrm{mmol} / \mathrm{l}, \mathrm{pH}=4.85)(32: 68 \mathrm{v} / \mathrm{v})$, then it was filtered through nylon membrane filter $0.45 \mu \mathrm{m}(47 \mathrm{~mm})$ and degassed before use.

\section{Preparation of stock solution, calibration standards and quality} control samples

A primary standard stock solution of colchicine $(200000 \mathrm{ng} / \mathrm{ml})$ was prepared by dissolving $4 \mathrm{mg}$ of colchicine powder in $20 \mathrm{ml}$ of the mobile phase, the solution was then vortexed and sonicated for 5 min. The standard stock solution was further diluted with the mobile phase to obtain a working standard solution of $60000 \mathrm{ng} / \mathrm{ml}$. Solutions for the calibration were prepared by diluting the working standard solution with the mobile phase to give concentrations in the range of 40 to $8000 \mathrm{ng} / \mathrm{ml}$. Three concentrations for the quality control (QC) were prepared at a low, medium and high concentration of 1000,4000 and $7000 \mathrm{ng} / \mathrm{ml}$, respectively.

\section{Preparation of the ethosomal gel nano-formulation}

The ethosomal gel was prepared using the cold method [6]. Briefly, Phospholipon $90 \mathrm{G}^{\circledast}$ and Tween $20^{\circledR}$ were taken in a small round bottom flask and solubilized with ethanol under mixing with a magnetic stirrer. Colchicine containing aqueous phase was added slowly with continuous stirring to obtain the ethosomal system formulation. The ethosomal system was further subjected to extrusion to get the nano-sized vesicles and then incorporated into Carbopol $940^{\circledR}$ gel base by manual mixing. Blank ethosomal gel formulation is identical to colchicine ethosomal gel but contains no colchicine, was prepared using the same preparation method as the colchicine ethosomal gel nano-formulation.

\section{System suitability studies}

The system suitability test was performed to verify reproducibility and the good performance of the chromategraphic system. The chromatographic parameters, such as, theoretical plates $(\mathrm{N})$, height equivalent to the theoretical plate (HETP) and tailing factor (T) were calculated as per the United States pharmacopoeia (USP) and checked at the three QC concentrations in six injection replicates.

\section{Specificity}

The possibility of interferences from mobile phase, ethosomal gel excipients and dissolution media at the retention time of colchicine was assessed by comparing the chromatograms obtained from the standard colchicine solution, mobile phase, blank ethosomal gel formulation, and the in vitro release dissolution media (phosphate buffer saline $\mathrm{pH}=6.4$ ).

\section{Stress degradation studies}

Stress degradation study of the drug helps to identify the degradation products, the stability of the molecule and specificity of the analytical procedure. Stress degradation studies under the conditions of acid, base, oxidation, heat and light as per the ICH guidelines [29] were performed on four solutions, namely: colchicine in standard solution and in the ethosomal gel formulation (sample) in addition to the mobile phase and the blank ethosomal gel. Colchicine standard solution of $6000 \mathrm{ng} / \mathrm{ml}$ was prepared and used for the study. Colchicine ethosomal gel sample $(0.5 \mathrm{~g})$ was dispersed in $20 \mathrm{ml}$ ultrapure water. Then the required volume was taken and diluted with the mobile phase to get the final concentration of $6000 \mathrm{ng} / \mathrm{ml}$. This method was also used to prepare the blank ethosomal gel sample. The mobile phase was used as it is.

\section{Acid and alkali degradation studies}

For acid degradation study, two sets of four $10 \mathrm{ml}$ flasks were filled in with $1 \mathrm{ml}$ of colchicine standard, colchicine ethosomal gel, blank ethosomal gel or mobile phase, respectively. Subsequently, $1 \mathrm{ml}$ of 0.5 $\mathrm{mol} / \mathrm{l} \mathrm{HCl}$ was added to all the flasks. The solutions in the first set were neutralized immediately with $1 \mathrm{ml}$ of $0.5 \mathrm{~mol} / \mathrm{l} \mathrm{NaOH}$, the mobile phase was added up to $10 \mathrm{ml}$ and served as zero hour samples. The solutions in the second set were left on the bench at room temperature $\left(25 \pm 2{ }^{\circ} \mathrm{C} / 65 \%\right.$ relative humidity) for $24 \mathrm{~h}$, then neutralized by the same way and the mobile phase was added up to $10 \mathrm{ml}$ and served as $24 \mathrm{~h}$ samples. All the samples were injected in triplicate. For the alkali degradation study, a similar procedure was used, but $1 \mathrm{ml}$ of $0.5 \mathrm{~mol} / \mathrm{l}$ $\mathrm{NaOH}$ was added to each flask instead of $1 \mathrm{ml}$ of $0.5 \mathrm{~mol} / \mathrm{l} \mathrm{HCl}$ and the neutralization procedure was done using $0.5 \mathrm{~mol} / \mathrm{l} \mathrm{HCl}$.

\section{Oxidative hydrogen peroxide $\left(\mathrm{H}_{2} \mathrm{O}_{2}\right)$ degradation}

Two sets of four $10 \mathrm{ml}$ flasks were filled in with $1 \mathrm{ml}$ of colchicine standard, colchicine ethosomal gel, blank ethosomal gel or mobile phase, respectively. Subsequently, $1 \mathrm{ml}$ of $3 \% \mathrm{H}_{2} \mathrm{O}_{2}$ was added to all the flasks. The solutions in the first set were immediately added with mobile phase up to $10 \mathrm{ml}$ and served as zero hour samples. The solutions in the second set were left on the bench at room temperature $\left(25 \pm 2{ }^{\circ} \mathrm{C} / 65 \%\right.$ relative humidity) for $24 \mathrm{~h}$, then mobile phase was added up to $10 \mathrm{ml}$ and served as $24 \mathrm{~h}$ samples. All the samples were injected in triplicate.

\section{Heat degradation study}

Two sets of four $10 \mathrm{ml}$ flasks were filled in with $1 \mathrm{ml}$ of colchicine standard, colchicine ethosomal gel, blank ethosomal gel or mobile phase, respectively. The solutions in the first set were immediately added with mobile phase up to $10 \mathrm{ml}$ and served as zero hour samples. The solutions in the second set were heated in a water bath at $80{ }^{\circ} \mathrm{C}$ for $2 \mathrm{~h}$, then mobile phase was added up to $10 \mathrm{ml}$ and served as $2 \mathrm{~h}$ samples. All the samples were injected in triplicate.

\section{Light degradation}

Two sets of four $10 \mathrm{ml}$ flasks were filled in with $1 \mathrm{ml}$ of colchicine standard, colchicine ethosomal gel, blank ethosomal gel or mobile phase, respectively. The solutions in the first set were immediately added with the mobile phase up to $10 \mathrm{ml}$ and served as zero hour samples. The solutions in the second set were stored in a UV cabinet ( $365 \mathrm{~nm}$ ) for $24 \mathrm{~h}$, then mobile phase was added up to $10 \mathrm{ml}$ and served as $24 \mathrm{~h}$ samples. All samples were injected in triplicate.

\section{Method validation}

\section{Linearity}

In order for the present HPLC method to be suitable for the assay, content uniformity and in vitro release tests, the range of linearity 
was extended to be in the range of around 0.5 to $130 \%$ of the target concentration of the drug $(6000 \mathrm{ng} / \mathrm{ml})$. Accordingly, the calibration curve was prepared using six solutions of colchicine at concentrations of 40, 100, 500, 2000, 5000 and $8000 \mathrm{ng} / \mathrm{ml}$. Each solution was injected in triplicate. The standard calibration curves for concentration versus peak area were constructed. The homoscedasticity assumption of the linear regression was tested by performing the (F-test) and the linearity was evaluated by weighted least squares regression analysis [30].

\section{Precision and accuracy}

Three levels of quality control (QC) samples of colchicine namely low, medium and high concentrations of 1000, 4000 and $7000 \mathrm{ng} / \mathrm{ml}$ were prepared from the stock solution and used to determine the method precision and accuracy. For intra-day precision and accuracy, three sets of standard solutions were injected on the same day. For inter-day precision and accuracy, three sets of standard solutions were injected over six consecutive days. Precision is defined as the percentage of the relative standard deviation (\%RSD) and calculated by dividing the standard deviation of the calculated concentration by the mean value. While accuracy was presented as the relative percentage of error (\%RE) and calculated by dividing the difference between calculated and nominal concentrations of the standard solution with the nominal concentration of the standard solution.

\section{Limit of detection (LOD) and limit of quantification (LOQ)}

The LOD is the lowest amount of analyte that can be detected in a sample, whereas the LOQ is the lowest amount of the analyte that can be quantified in a sample with acceptable accuracy and precision [31]. These were determined by serial dilutions of colchicine stock solutions in order to obtain a signal to noise $(\mathrm{S} / \mathrm{N})$ ratio of at least 3.3:1 for LOD and 10:1 for LOQ.

\section{Robustness}

The robustness of the developed method was evaluated by deliberately making slight changes in the optimized value of the chromatographic conditions. The evaluated variables were namely: detector wavelength $( \pm 2 \mathrm{~nm}), \mathrm{pH}( \pm 0.2)$, the composition of the mobile phase $( \pm 1 \mathrm{v} / \mathrm{v})$, flow rate $( \pm 0.1 \mathrm{ml} / \mathrm{min})$ and oven temperature $\left( \pm 2{ }^{\circ} \mathrm{C}\right)$. Colchicine concentration of $4000 \mathrm{ng} / \mathrm{ml}$ was used to perform the study. Colchicine peak areas and the \%RSD of robustness testing under these conditions were calculated in all cases and the obtained data were analyzed statistically.

\section{Stock solution stability}

The stock solution of colchicine (200 $000 \mathrm{ng} / \mathrm{ml})$ was kept for $24 \mathrm{~h}$ at room temperature $\left(25 \pm 2{ }^{\circ} \mathrm{C}\right)$. The stock solution was then diluted to a concentration within the standard calibration curve range of $4000 \mathrm{ng} / \mathrm{ml}$. The responses at $24 \mathrm{~h}$ were compared with that of freshly prepared samples at zero hours.

\section{Quantification of colchicine content in the ethosomal gel}

Colchicine ethosomal gel $(0.5 \mathrm{~g})$ was dispersed in $20 \mathrm{ml}$ of ultrapure water under continuous mixing with a magnetic stirrer for $60 \mathrm{~min}$. The solution was then sonicated in an ultrasonic bath (Branson 5510, USA) for $10 \mathrm{~min}$. A suitable aliquot was removed and diluted with the mobile phase to get the final nominal concentration of 6000 $\mathrm{ng} / \mathrm{ml}$ and subjected to chromatographic analysis. The drug peak area was referred to the regression equation to get the sample concentration.

\section{Recovery of colchicine}

The blank ethosomal gel formulation $(0.5 \mathrm{~g})$ was dispersed in $20 \mathrm{ml}$ of ultrapure water, and then $1.2 \mathrm{mg}$ of colchicine (as this amount is equivalent to the amount of colchicine that should be contained in $0.5 \mathrm{~g}$ of the colchicine ethosomal gel) was added to the solution under continuous mixing with a magnetic stirrer. The solution was then sonicated in an ultrasonic bath for $10 \mathrm{~min}$.

Then $1 \mathrm{ml}$ of this solution was diluted with the mobile phase in a 10 $\mathrm{ml}$ volumetric flask and filtered with $0.45 \mu \mathrm{m}$ pore size nylon filter to give a final nominal concentration of $6000 \mathrm{ng} / \mathrm{ml}$. The sample of $10 \mu \mathrm{l}$ was injected into the HPLC system. The drug peak area was referred to the regression equation to calculate the recovery. The analysis was done in triplicate.

\section{Statistics}

All the statistical tests of the developed method including the weighted linear regression analysis of the calibration curves, the one-way analysis of variance (ANOVA) and a post hoc Tukey's HSD (honest significant difference) were performed using Minitab ${ }^{\circledR}$ software to analyze the results of the robustness and stock solution stability studies. The difference was statistically significant when $\mathrm{p}<0.05$ and all values were expressed as mean $\pm S \mathrm{~S}$.

\section{RESULTS}

\section{System suitability studies}

The results of retention time, tailing factor (T), theoretical plates $(\mathrm{N})$, and a height equivalent to the theoretical plate (HETP), of the method at three QC concentrations, are shown in table 1 . The peak retention time was about $5.9 \mathrm{~min}$, the average theoretical plate was $>4500$ and the tailing factor was $<2$, which means that the method met the requirements stated in the United States pharmacopeia [1].

Table 1: Results of system suitability studies of quality control samples of colchicine

\begin{tabular}{|c|c|c|c|c|c|c|c|c|}
\hline Conc. (ng/ml) & Retention time $^{\mathbf{a}}$ & \%RSD & $\mathbf{T}^{\mathbf{a}}$ & \%RSD & $\mathbf{N}^{\mathbf{a}}$ & \%RSD & HETPa & \%RSD \\
\hline 1000 & $5.935 \pm 0.0008$ & 0.01 & $1.057 \pm 0.0024$ & 0.23 & $12591.33 \pm 24.22$ & 0.19 & $19.86 \pm 0.04$ & 0.19 \\
\hline 4000 & $5.933 \pm 0.0011$ & 0.02 & $1.060 \pm 0.0004$ & 0.04 & $12736.67 \pm 13.94$ & 0.11 & $19.63 \pm 0.02$ & 0.11 \\
\hline 7000 & $5.933 \pm 0.0016$ & 0.03 & $1.063 \pm 0.0006$ & 0.05 & $12776.50 \pm 32.69$ & 0.26 & $19.57 \pm 0.05$ & 0.26 \\
\hline
\end{tabular}

${ }^{a}$ mean $\pm S D, n=6$; T: Tailing factor; $N$ : Theoretical plate number; HETP: Height equivalent to the theoretical plate.

\section{Specificity}

Fig. 2 shows the representative chromatograms of the mobile phase (A), standard solution of colchicine at a concentration of $6000 \mathrm{ng} / \mathrm{ml}(\mathrm{B})$, blank ethosomal gel (C), colchicine ethosomal gel at a concentration of $6000 \mathrm{ng} / \mathrm{ml}$ (D) and phosphate buffer saline $\mathrm{pH}=6.4$ for the in vitro dissolution media (E). The chromatogram of the colchicine loaded ethosomal gel (fig. 2, D) showed a peak and retention time (5.9 min) similar to colchicine standard solution (fig. 2, B). No interference from mobile phase, blank ethosomal gel formulation (excipients) and the dissolution media were detected at the retention time of colchicine (fig. 2, A, C and E) indicating that the method is highly selective and specific in relation to the medium and excipients used in this study.

\section{Stress degradation studies}

The results of the stress degradation studies (acid, alkali, oxidation, heat and light) for the standard solution and the ethosomal gel formulation are shown in table 2. The chromatograms of the stressed standard colchicine solution and colchicine ethosomal gel formulation after $24 \mathrm{~h}$ under the different stress conditions are shown in fig. 3 and 4 . The drug showed good stability under heat, acid, oxidation and light, but substantial degradation was observed under the alkali condition (fig. 3, B and fig. 4, B). The percentage of drug in the standard solution and ethosomal gel was reduced significantly to $1.63 \pm 0.04$ and $1.48 \pm 0.02$ after $24 \mathrm{~h}$, respectively. 

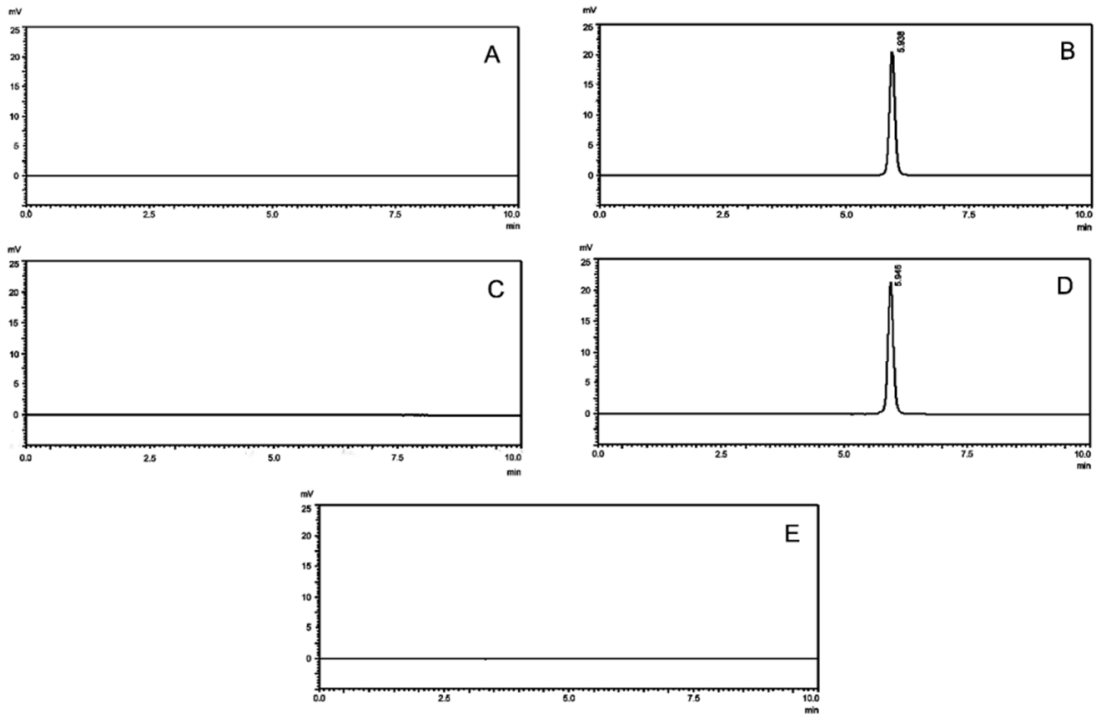

Fig. 2: Chromatograms of A: Mobile phase, B: Standard colchicine solution (6000 ng/ml), C: Blank ethosomal gel, D: Colchicine ethosomal gel (6000 ng/ml), E: Phosphate buffer saline solution

Table 2: Results of the stress degradation studies

\begin{tabular}{|c|c|c|c|c|}
\hline \multicolumn{5}{|c|}{ Stress degradation studies' results for the standard colchicine solution at 0 and $24 \mathrm{~h}$} \\
\hline Forced degradation condition & Time (h) & Remaining drug (\%) ${ }^{a}$ & Time (h) & Remaining drug (\%) ${ }^{\mathrm{a}}$ \\
\hline Acid $(0.5 \mathrm{~mol} / \mathrm{l} \mathrm{HCl})$ & 0 & $99.29 \pm 0.27$ & 24 & $97.8 \pm 0.38$ \\
\hline Base $(0.5 \mathrm{~mol} / \mathrm{l} \mathrm{NaOH})$ & 0 & $99.05 \pm 0.36$ & 24 & $1.63 \pm 0.04$ \\
\hline Oxidation $\left(3 \% \mathrm{H}_{2} \mathrm{O}_{2}\right)$ & 0 & $99.82 \pm 0.07$ & 24 & $97.98 \pm 0.14$ \\
\hline Light (365 nm) & 0 & $99.96 \pm 0.08$ & 24 & $99.50 \pm 0.06$ \\
\hline Heat $\left(80^{\circ} \mathrm{C}\right)$ & 0 & $99.96 \pm 0.08$ & 2 & $100.01 \pm 0.46$ \\
\hline \multicolumn{5}{|c|}{ Stress degradation studies' results for the colchicine loaded ethosomal gel formulation at 0 and $24 \mathrm{~h}$} \\
\hline Forced degradation condition & Time (h) & Remaining drug (\%) & Time (h) & Remaining drug (\%) \\
\hline Acid $(0.5 \mathrm{~mol} / \mathrm{l} \mathrm{HCl})$ & 0 & $99.55 \pm 0.24$ & 24 & $96.78 \pm 0.09$ \\
\hline Base $(0.5 \mathrm{~mol} / \mathrm{l} \mathrm{NaOH})$ & 0 & $97.55 \pm 0.02$ & 24 & $1.48 \pm 0.02$ \\
\hline Oxidation $\left(3 \% \mathrm{H}_{2} \mathrm{O}_{2}\right)$ & 0 & $98.05 \pm 0.02$ & 24 & $99.84 \pm 0.02$ \\
\hline Light $(365 \mathrm{~nm})$ & 0 & $99.96 \pm 0.04$ & 24 & $98.96 \pm 0.05$ \\
\hline Heat $\left(80^{\circ} \mathrm{C}\right)$ & 0 & $99.96 \pm 0.04$ & 2 & $99.77 \pm 0.07$ \\
\hline
\end{tabular}

Heat $\left(80^{\circ} \mathrm{C}\right)$

$99.96 \pm 0.04$

$99.77 \pm 0.07$

${ }^{\mathrm{a}}$ mean $\pm \mathrm{SD}, \mathrm{n}=3$.
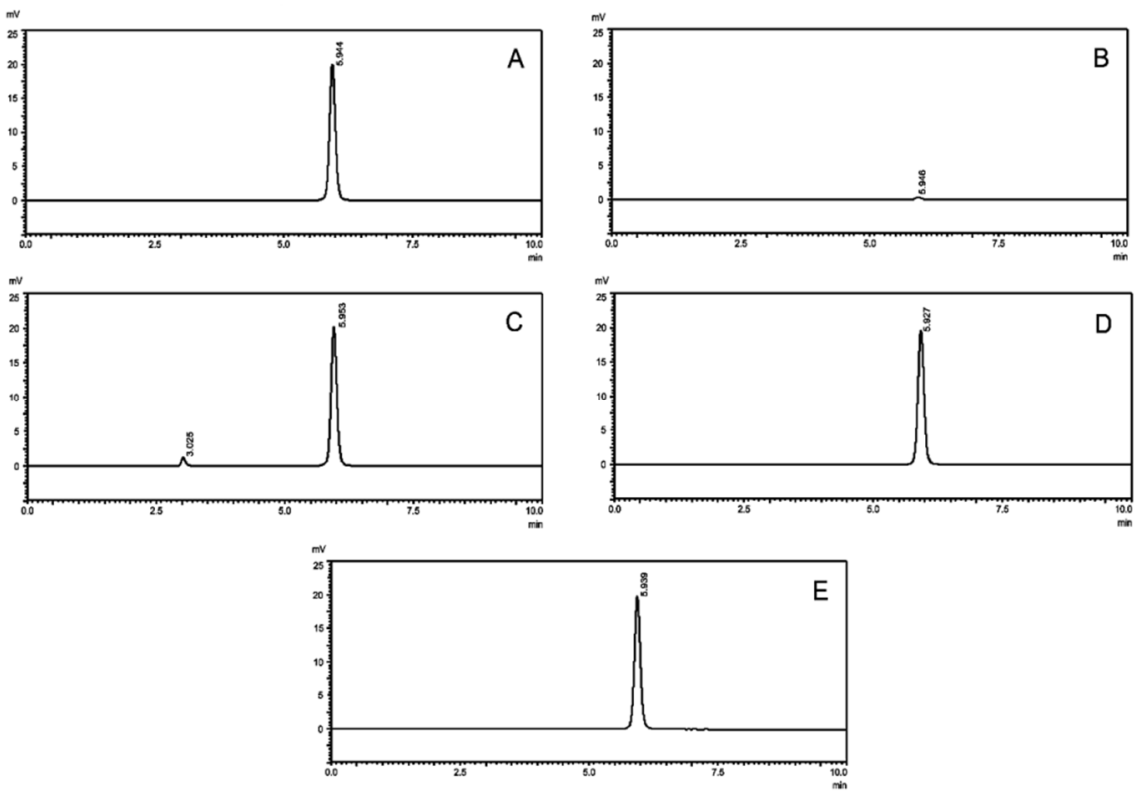

Fig. 3: Chromatograms of stressed standard colchicine solution under A: Acid (0.5 mol/l HCl after 24 h), B: Base (0.5 mol/1 NaOH after 24 h), C: Oxidation ( $3 \% \mathrm{H}_{2} \mathrm{O}_{2}$ after $\left.24 \mathrm{~h}\right)$, D: Light (365 nm after $\left.24 \mathrm{~h}\right)$, E: Heat $\left(80{ }^{\circ} \mathrm{C}\right.$ after $\left.2 \mathrm{~h}\right)$ 

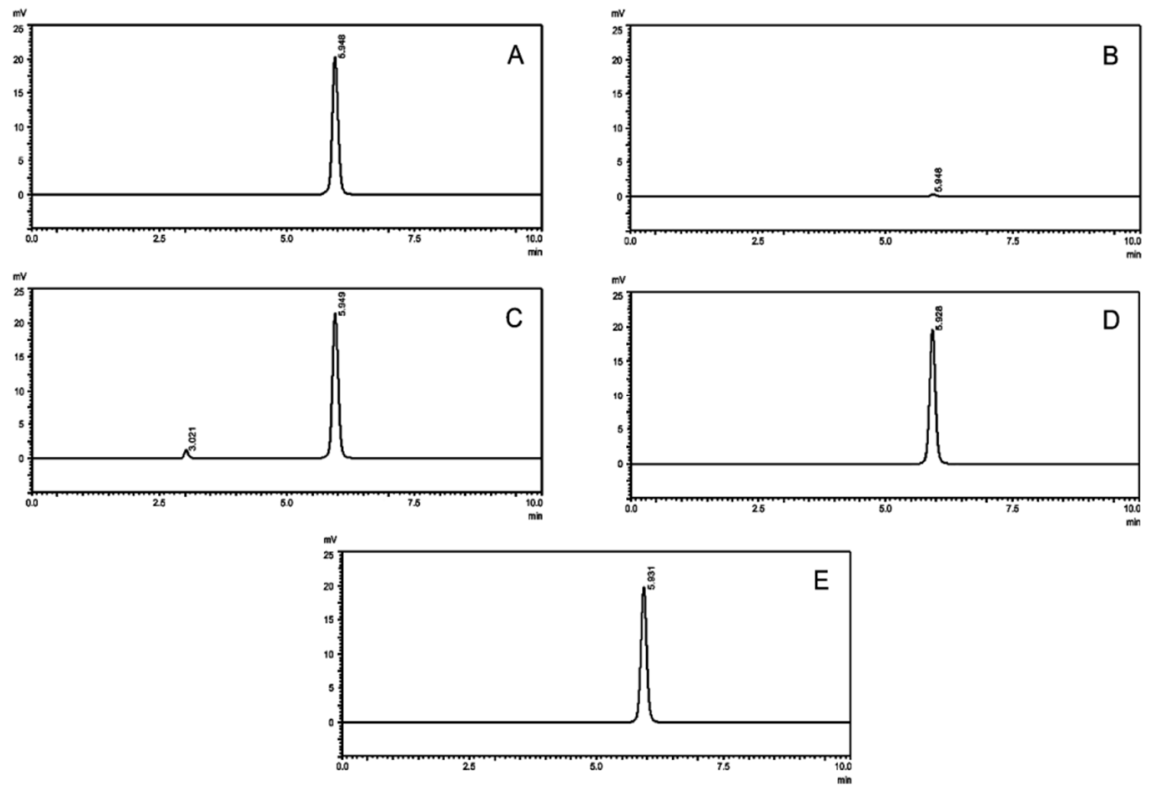

Fig. 4: Chromatograms of the stressed colchicine ethosomal gel samples under A: Acid (0.5 mol/1 $\mathrm{HCl}$ after $24 \mathrm{~h}), \mathrm{B}: \mathrm{Base}(0.5 \mathrm{~mol} / \mathrm{l} \mathrm{NaOH}$ after $24 \mathrm{~h}$ ), C: Oxidation: ( $3 \% \mathrm{H}_{2} \mathrm{O}_{2}$ after $\left.24 \mathrm{~h}\right)$, D: Light ( $365 \mathrm{~nm}$ after $\left.24 \mathrm{~h}\right)$, E: Heat ( $80^{\circ} \mathrm{C}$ after $2 \mathrm{~h}$ )

\section{Linearity}

The results of the variance test (F-test) confirmed the presence of hetero scedasticity (i.e. F (experimental) $>\mathrm{F}$ (tabulated)). So weighted linear regression was applied using the following weighting factors $\left(\mathrm{w}_{\mathrm{i}}\right) 1,1 / \mathrm{x}, 1 / \mathrm{x}^{2}, 1 / \mathrm{x}^{1 / 2}, 1 / \mathrm{y}, 1 / \mathrm{y}^{2}$ and $1 / \mathrm{y}^{1 / 2}$. The best regression model and weighting factor were selected by comparing the sum of absolute percentage relative error (\%RE) values of all models and the results are shown in table 3 . A regression model with a weighting factor of $1 / \mathrm{x}^{2}$ was chosen as it showed the least sum of the $\% \mathrm{RE}$ across the whole concentration range. The linear regression equation was $y=$ $27.093 x+53.1$ with a correlation coefficient of 0.9998 .

Table 3: Weighted least squares regression analysis

\begin{tabular}{|c|c|c|c|c|c|c|c|}
\hline $\mathbf{w}_{\mathbf{i}}$ & 1 & $1 / x$ & $1 / x^{2}$ & $1 / x^{1 / 2}$ & $1 / y$ & $1 / y^{2}$ & $1 / y^{1 / 2}$ \\
\hline $\mathrm{a}^{\mathrm{a} \pm \mathrm{SD}}$ & $27.612 \pm 0.571$ & $27.656 \pm 0.566$ & $27.591 \pm 0.653$ & $27.639 \pm 0.565$ & $27.655 \pm 0.566$ & $27.583 \pm 0.657$ & $27.639 \pm 0.565$ \\
\hline$b^{a} \pm S D$ & $138.666 \pm 284.682$ & $24.3 \pm 11.227$ & $34.713 \pm 23.707$ & $41.333 \pm 56.922$ & $22.933 \pm 10.005$ & $33.063 \pm 22.613$ & $40.666 \pm 56.887$ \\
\hline Mean $\mathrm{R}^{2}$ & 0.9999 & 0.9999 & 0.9995 & 0.9999 & 0.9999 & 0.9995 & 0.9999 \\
\hline$\sum \% \mathrm{RE}$ & 115.846 & 22.561 & 19.814 & 23.450 & 22.813 & 20.302 & 30.698 \\
\hline
\end{tabular}

${ }^{a}$ mean $\pm S D, n=3 ; w_{i}$ : Weighting factor; a: Slope of regression line; b: Intercept of regression line; $\mathrm{R}^{2}$ : Correlation coefficient; RE: Relative error.

\section{Precision and accuracy}

The obtained results of the Intra-day and inter-day precision and accuracy are shown in table 4 . The intra-day precision for colchicine ranged between $0.04 \%$ and $0.15 \%$, while the accuracy was between
$-0.04 \%$ and $0.39 \%$. The inter-day precision ranged between $0.14 \%$ and $0.24 \%$, while the accuracy was between $0.09 \%$ and $0.39 \%$. The data showed a good degree of precision and accuracy of the method and within the $\pm 2 \%$ range recommended by the United States pharmacopeia [1].

Table 4: Results of intra-day and inter-day precision and accuracy

\begin{tabular}{llllll}
\hline $\begin{array}{l}\text { Theoretical conc. } \\
\text { (ng/ml) }\end{array}$ & Intra-day & & \multicolumn{2}{l}{ Inter-day } \\
\cline { 2 - 6 } & $\begin{array}{l}\text { Found conc. } \\
\text { (ng/ml) }\end{array}$ & Precision (\%RSD) & Accuracy (\%RE) & $\begin{array}{l}\text { Found conc. } \\
\text { (ng/ml) }\end{array}$ & Precision (\%RSD) \\
\hline 1000 & $1003.89 \pm 0.42$ & 0.04 & 0.39 & $1000.94 \pm 2.37$ & 0.24 \\
4000 & $3998.43 \pm 2.96$ & 0.07 & -0.04 & $4004.92 \pm 5.77$ & 0.14 \\
7000 & $7007.64 \pm 10.53$ & 0.15 & 0.11 & $7027.68 \pm 15.32$ & 0.22 \\
\hline
\end{tabular}

amean $\pm S D, n=6$.

\section{Limit of detection (LOD) and limit of quantification (LOQ)}

The LOD and LOQ of colchicine in the present method were found to be $8.64 \mathrm{ng} / \mathrm{ml}$ and $26.17 \mathrm{ng} / \mathrm{ml}$, respectively.

\section{Robustness}

The results of robustness study are presented in table 5. The statistical tests showed that the variations in the $\mathrm{pH}$ of the mobile phase and oven temperature did not significantly affect the peak area or the retention time.

On the other hand, the variation in the wavelength of the detection, and flow rate caused significant variations in the peak area and retention time, while the variation in mobile phase composition of acetonitrile did not influence the peak area, but caused significant shifting in the retention time. 
Table 5: Analysis of method robustness using colchicine at a concentration of $4000 \mathrm{ng} / \mathrm{ml}$

\begin{tabular}{|c|c|c|c|c|c|}
\hline Parameters & Changes & Mean are $a^{a} \pm$ SD & \%RSD & Mean retention time $(\min )^{\mathrm{a}} \pm \mathrm{SD}$ & \%RSD \\
\hline \multirow{3}{*}{ Detector wavelength $(\mathrm{nm})$} & 355 & $107895.33 \pm 64.34$ & 0.06 & $5.933 \pm 0.0008$ & 0.01 \\
\hline & 353 & $108523 \pm 80.05$ & 0.07 & $5.940 \pm 0.0026$ & 0.04 \\
\hline & 351 & $108497 \pm 78.26$ & 0.07 & $5.931 \pm 0.0005$ & 0.01 \\
\hline \multirow[t]{3}{*}{$\mathrm{pH}$ of the mobile phase } & 5.05 & $108640.33 \pm 141.8$ & 0.13 & $5.934 \pm 0.0062$ & 0.11 \\
\hline & 4.85 & $108436.33 \pm 83.65$ & 0.08 & $5.934 \pm 0.0012$ & 0.02 \\
\hline & 4.65 & $108639.33 \pm 70.87$ & 0.07 & $5.929 \pm 0.0062$ & 0.1 \\
\hline \multirow[t]{3}{*}{ Mobile phase composition (v/v) } & $(33: 67)$ & $108512.67 \pm 92.96$ & 0.09 & $5.599 \pm 0.0022$ & 0.04 \\
\hline & $(32: 68)$ & $108311.33 \pm 19.74$ & 0.02 & $5.935 \pm 0.0017$ & 0.03 \\
\hline & $(31: 69)$ & $108365.33 \pm 173.1$ & 0.16 & $6.332 \pm 0.0005$ & 0.01 \\
\hline \multirow[t]{3}{*}{ Flow rate $(\mathrm{ml} / \mathrm{min})$} & 1.1 & $99104.33 \pm 71.34$ & 0.07 & $5.427 \pm 0.0016$ & 0.03 \\
\hline & 1 & $108412.33 \pm 130.9$ & 0.12 & $5.932 \pm 0.0008$ & 0.01 \\
\hline & 0.9 & $120712.33 \pm 135.5$ & 0.11 & $6.555 \pm 0.0017$ & 0.03 \\
\hline \multirow[t]{3}{*}{ Temperature $\left({ }^{0} \mathrm{C}\right)$} & 32 & $108508.33 \pm 72.37$ & 0.07 & $5.933 \pm 0.0009$ & 0.02 \\
\hline & 30 & $108523 \pm 83.95$ & 0.08 & $5.933 \pm 0.0026$ & 0.04 \\
\hline & 28 & $108573.67 \pm 109.5$ & 0.1 & $5.929 \pm 0.0024$ & 0.04 \\
\hline
\end{tabular}

amean $\pm S D, n=3$.

\section{Stock solution stability}

The results showed that the percentage of colchicine remained after $24 \mathrm{~h}$ kept at room temperature $\left(25 \pm 2{ }^{\circ} \mathrm{C}\right)$ was $100.3 \pm 0.2 \%$. There was no statistical difference in peak area between the samples measured at zero time and after $24 \mathrm{~h}$ at $\left(25 \pm 2{ }^{\circ} \mathrm{C}\right)$, indicating that the stock solution was stable for at least $24 \mathrm{~h}$ at room temperature.

\section{Quantification of colchicine content in the ethosomal gel}

Colchicine content in the ethosomal gel formulation was found to be $99.86 \%$.

\section{Recovery studies of colchicine in the ethosomal gel}

The experiment was conducted to determine the accuracy of the present method for the quantification of colchicine sample. The recovery of colchicine was calculated from the slope and the intercept of the calibration curve drawn in the concentration range of $40-8000 \mathrm{ng} / \mathrm{ml}$. The percentage recovery of colchicine ranged between $99.54 \%$ and $99.76 \%$ in the ethosomal gel formulation sample.

\section{DISCUSSION}

In the development of an HPLC method, the separation of analyte should be optimized at a $\mathrm{pH}$ where the retention time of analyte is the least affected by $\mathrm{pH}$ changes. Accordingly, the buffer $\mathrm{pH}$ should be selected at least $\pm 1 \mathrm{pH}$ units from the $\mathrm{pK}_{\mathrm{a}}$ of the analyte. This is to ensure that the analyte is $100 \%$ ionized or $100 \%$ non-ionized at the selected $\mathrm{pH}$ for obtaining reproducible retention time of the analyte. Since the $\mathrm{pK}_{\mathrm{a}}$ of colchicine is 1.85 , thus in the early stages of method development, the $\mathrm{pH}$ value of 3.85 was studied. However, this $\mathrm{pH}$ is highly acidic and may damage certain HPLC columns that cannot tolerate such a low $\mathrm{pH}$ value. Therefore, a higher $\mathrm{pH}$ value was tried (4.85), and found that there was no significant difference in peak area of both tested $\mathrm{pH}$ values (i.e. 3.85 and 4.85). Accordingly, the $\mathrm{pH}$ value of 4.85 was selected as the optimized $\mathrm{pH}$ value of the method.

The solubility of the salt used in mobile phase composition should be considered in developing an HPLC method, especially if acetonitrile (the commonly used organic solvent) is present in the mobile phase. In comparison to other studies [16-18, 20], ammonium acetate buffer was selected in this study as it is more soluble in acetonitrile than phosphate buffers. Phosphate buffers may precipitate when mixed with acetonitrile, and this will affect the function of the column and the HPLC device.

Different oven temperatures of $25,30,35$ and $40{ }^{\circ} \mathrm{C}$ were also studied during the optimization of the method. The temperature of $30{ }^{\circ} \mathrm{C}$ was found to be the optimum oven temperature as good separation, peak shape and area were obtained.

Several HPLC-UV methods for the quantification of colchicine in pharmaceuticals or biological fluids have been published [12, 14-21]. However, to the best of our knowledge, this is the first developed stability indicating HPLC-UV method for detection and quantification of colchicine. The results of the stress degradation studies confirmed the high specificity of the method for colchicine and revealed that colchicine is highly susceptible to alkali degradation and this might be attributed to the acidic nature of the drug $\left(\mathrm{pK}_{\mathrm{a}}=1.85\right)$.

The extended linearity range $(0.5$ to $130 \%)$ made the method suitable for the assay, content uniformity and in vitro release tests. The LOD $(8.64 \mathrm{ng} / \mathrm{ml})$ and LOQ $(26.17 \mathrm{ng} / \mathrm{ml})$ obtained in the present study were the lowest values among the previously published methods for the quantification of colchicine in pharmaceutical formulations [12, 14-17]. The intra and inter-day accuracy and precision were $<1 \%$, reflecting the high accuracy of the protocol, and that it is meeting the United States pharmacopeia recommendations [1].

\section{CONCLUSION}

A sensitive, simple, specific and stability indicating HPLC-UV method for determination of colchicine in bulk and ethosomal gel nano-formulation was successfully developed. The Statistical analysis confirmed that the method was accurate, precise, and reproducible. No peaks interferences with colchicine by the formulation excipients, diluents, dissolution media or degradation products were detected. Colchicine was found to be stable against acid, oxidation, heat and light, but it is highly susceptible to alkali degradation. The method could be used for the routine assay, content uniformity, and the in vitro release studies of colchicine from the ethosomal gel nano-formulation.

\section{ACKNOWLEDGEMENT}

The authors would like to thank Universiti Sains Malaysia for providing research university grant (1001/PFarmasi/811285) to support this work. The author (Ibrahim M. Abdulbaqi) gratefully acknowledges Universiti Sains Malaysia, Penang, Malaysia for awarding of the graduate assistantship.

\section{CONFLICT OF INTERESTS}

The authors declare no conflict of interest

\section{REFERENCES}

1. The United States Pharmacopoeia and National Formulary. 38th ed. The United States Pharmacopeial Convention, Rockville, MD, USA; 2015. p. 2934-5.

2. Echteld IV, Wechalekar MD, Schlesinger N, Buchbinder R, Aletaha D. Colchicine for acute gout. Cochrane Database Syst Rev 2014;8:1-41.

3. Terkeltaub RA. Colchicine update: 2008. Semin Arthritis Rheum 2009;38:411-9.

4. Naseri A, Karami M, Nadoushan MJ. Failing of information transmission by dorsal hippocampus due to microinjection of colchicine in rat's cortical area 1. Asian J Pharm Clin Res 2015;4:160-3. 
5. Kesselheim AS, Solomon DH. Incentives for the drug development the curious case of colchicine. N Engl J Med 2010;362:2045-7.

6. Abdulbaqi IM, Darwis Y, Khan NAK, Assi RA, Khan AA. Ethosomal nanocarriers: the impact of constituents and formulation techniques on ethosomal properties, in vivo studies, and clinical trials. Int J Nanomed 2016;11:2279-304.

7. Shaji J, Garude S. Transethosomes and ethosomes for enhanced transdermal delivery of ketorolac tromethamine: a comparative assessment. Int J Curr Pharm Res 2014;6:88-93.

8. Toppo FA, Pawar RS. Novel drug delivery strategies and approaches for wound healing managements. J Crit Rev 2015;2:12-20.

9. Fleischmann W, Price HG, Fleischmann SK. Fate of intraperitoneally administered colchicine in the Mongolian gerbil. Pharmacology 1967;17:323-6.

10. Arai T, Okuyama T. Fluorometric assay of the tubulincolchicine complex. Anal Biochem 1975;69:443-50.

11. Boudene C, Duprey F, Bohuon C. Radioimmunoassay of colchicine. Biochem J 1975;151:413-5.

12. Sarg TM, El-Domiaty MM, Bishr MM, Salama OM, El-Gindy AR. Thin-layer chromatographic scanner, spectrophotometric and high-performance liquid chromatographic methods for the determination of colchicine. Analyst 1989;114:575-8.

13. Bodoki E, Oprean R, Vlase L, Tamas M, Sandulescu R. Fast determination of colchicine by TLC-densitometry from pharmaceuticals and vegetal extracts. J Pharm Biomed Anal 2005;37:971-7.

14. Samanidou VF, Sarantis GA, Papadoyannis IN. Development and validation of a rapid HPLC method for the direct determination of colchicine in pharmaceuticals and biological fluids. J Liq Chromatogr Relat Technol 2006;29:1-13.

15. Nirmala K, Raju RR. A novel method development for validation and detection of colchicine drug by RP-HPLC. Rasayan J Chem 2012;5:106-11.

16. Hadad GM, Badr JM, El-Nahriry K, Hassanean HA. Validated HPLC and HPTLC methods for simultaneous determination of colchicine and khellin in pharmaceutical formulations. J Chromatogr Sci 2013;51:258-65.

17. Chandrethiya GD, Shelat PK, Zaveri MN. RP-HPLC method development and validation for estimation of colchicine in gelatin nanoparticles formulation. Int J Pharm Pharm Sci 2013;5 Suppl 1:228-31

18. Klein AE, Davis PJ. Determination of colchicine and colchiceine in microbial cultures by high-performance liquid chromatography. Anal Chem 1980;52:2432-5.

19. Lhermitte M, Bernier JL, Mathieu D, Mathieu-Nolf M, Erb F, Roussel P. Colchicine quantitation by high-performance liquid chromatography in human plasma and urine. J Chromatogr B Biomed Sci Appl 1985;342:416-23.

20. Fernandez P, Bermejo AM, Tabernero MJ, López-Rivadulla M, Cruz A. Determination of colchicine in biological fluids by reverse-phase HPLC. Variation of colchicine levels in rats. Forensic Sci Int 1993;59:15-8.

21. Chen QH, Hou S, Gan LC, Li YB, Song X, Cai Z. Determination of colchicine in mouse plasma by a high-performance liquid chromatographic method with UV detection and its application to pharmacokinetic studies. Yakugaku Zasshi 2007;127:1485-90.

22. Tracqui A, Kintz P, Ludes B, Rougé C, Douibi H, Mangin P. Highperformance liquid chromatography coupled to ion spray mass spectrometry for the determination of colchicine at ppb levels in human biofluids. J Chromatogr B Biomed Sci 1996;675:235-42.

23. Jones GR, Singer PP, Bannach B. Application of LC-MS analysis to a colchicine fatality. J Anal Toxicol 2002;26:365-9.

24. Abe E, Lemaire-Hurtel A, Duverneuil C, Etting I, Guillot E, Mazancourt $\mathrm{P}$, et al. A novel LC-ESI-MS-MS method for sensitive quantification of colchicine in human plasma: application to two case reports. J Anal Toxicol 2006;30:210-5.

25. Hamscher G, Priess B, Nau H, Panariti E. Determination of colchicine residues in sheep serum and milk using highperformance liquid chromatography combined with electrospray ionization ion trap tandem mass spectrometry. Anal Chem 2005;77:2421-5.

26. Chèze $M$, Deveaux $M$, Pépin G. Liquid chromatography-tandem mass spectrometry for the determination of colchicine in postmortem body fluids. Case report of two fatalities and review of the literature. J Anal Toxicol 2006;30:593-8.

27. Jiang Y, Wang J, Wang Y, Li H, Fawcett JP, Gu J. Rapid and sensitive liquid chromatography-tandem mass spectrometry method for the quantitation of colchicine in human plasma. J Chromatogr B 2007;850:564-8.

28. Clevenger CV, August TF, Shaw LM. Colchicine poisoning: report of a fatal case with body fluid analysis by GC/MS and histopathologic examination of postmortem tissues. J Anal Toxicol 1991;15:151-4.

29. International conference on harmonization of technical requirements for registration of pharmaceuticals for human use. Validation of analytical procedures: text and methodology. ICH Q2 (R1); 2005.

30. Almeida AM, Castel-Branco MM, Falcão AC. Linear regression for calibration lines revisited: weighting schemes for bioanalytical methods. J Chromatogr B 2002;774:215-22.

31. Tijare LK, Rangari NT, Mahajan UN. A review on bioanalytical method development and validation. Asian J Pharm Clin Res 2016;9 Suppl 3:6-10.

\section{How to cite this article}

- Ibrahim M Abdulbaqi, Yusrida Darwis, Nurzalina Abdul Karim Khan, Reem Abou Assi, Gabriel Onn Kit Loh. A simple (HPLCUV) method for the quantification of colchicine in bulk and ethosomal gel nano-formulation and its validation. Int J Pharm Pharm Sci 2017;9(7):72-78. 